\title{
30 AÑOS CONSTRUYENDO EL RÉGIMEN DE SEGURIDAD INFORMAL PARAGUAYO
}

30 YEARS BUILDING THE REGIME PARAGUAYAN

INFORMAL SECURITY

\section{José Antonio Rojas Caballero ${ }^{1}$ Ana Teresa Rojas Viñales ${ }^{2}$}

Enviado: $18 / 12 / 2020$

Aceptado: 9/3/2021

Resumen: En el 2019, Paraguay cumplió 30 años de transición democrática y, si bien, se reconocen avances en varios de los aspectos, aún persisten muchas falencias en la gestión del Estado, y dudas sobre la capacidad de garantizar, para todos sus ciudadanos, a través de bienes, servicios y regulaciones lo establecido en la Constitución Nacional (art. 6). Este artículo tiene la finalidad de contribuir al área de políticas sociales en el Paraguay, conceptualizando, en primer lugar, los Estados/Regímenes de Bienestar y el Estado Paraguayo como unidad de análisis, resaltando sus características históricas, las relaciones Sociedad-Mercado y Estado y el fuerte vínculo con el clientelismo político en su formación y expansión a

${ }^{1}$ Escuela de Ciencias Sociales y Políticas, Universidad Nacional de Asunción. Contacto: jarcpy@gmail.com

2 Facultad de Ciencias Económicas, Universidad Nacional de Asunción. Contacto: aterovi@gmail.com 
partir de la mitad del S. XX, hasta nuestros días. En segundo lugar se revisan cómo estos conceptos desarrollados se materializan a través de las políticas sociales, sus características, principales estrategias, programas y proyectos emblemáticos implementados, y la evolución de la institucionalidad a lo largo de tres fases bien diferenciadas entre sí: a) el periodo correspondiente a los años 1989 al 2002, caracterizado por ser la fase inicial o incipiente de la intervención estatal en materia social; b) el segundo periodo del 2003 al 2013, inicio de los programas de lucha contra la pobreza, así como el afianzamiento de algunos programas/políticas universales y la expansión de los principales derechos sociales constitucionales; y c) el tercer periodo que corresponde a los años 2013 al 2018, cuando se da la ruptura y reconfiguración (tanto en lo conceptual como en lo programático-institucional) de la gestión estatal, en materia de políticas sociales.

Palabras clave: protección social; seguridad social; clientelismo; políticas sociales; Estados de Bienestar.

Abstract: In 2019, Paraguay celebrated 30 years of democratic transition and, although progress is recognized in various aspects, there are still many shortcomings of the State and doubts about the ability to guarantee, for all its citizens, through goods, services and regulations as is established in the Constitutional Law (art. 6th). This article aims to contribute to the area of social policies in Paraguay, first conceptualizing the States / Welfare Regimes and the Paraguayan State as a unit of analysis where its historical characteristics, the Society-Market and State relations and the strong link with political patronage in its formation and expansion from the middle of the 20th century to the present day. In a second block, we review how these concepts developed are materialized 
through social policies, their characteristics, main strategies, programs and emblematic projects implemented and the evolution of the institutionality throughout three stages or phases that are well differentiated from each other: a ) the period corresponding to the years 1989 to 2002 characterized by being the initial or incipient phase of state intervention in social matters; b) second stage from 2003 to 2013, start of programs to fight against poverty, as well as the consolidation of some universal programs \& politics and the expansion of the main constitutional social rights; and c) the period corresponding to the years 2013 to 2018, where there is a rupture and reconfiguration (both conceptually and programmatic- institutionally) of state management in terms of social policies.

Keywords: social protection; social Security; clientelism; social politics; Welfare States. 


\section{Introducción}

En 2019, Paraguay cumplió 30 años de transición democrática. Aunque se reconocen avances en varios de los aspectos, aún persisten muchas falencias en la gestión del Estado y dudas sobre la capacidad de garantizar, para todos sus ciudadanos, a través de bienes, servicios y regulaciones en lo establecido en la Constitución Nacional "De la calidad de vida" (art. 6 CN 1992).

Paraguay, ese que no se muestra al mundo, tiene alrededor de un cuarto de la población sumida en pobreza monetaria, $65 \%$ de la población económicamente activa trabajando de manera informal, y casi 8 de cada 10 paraguayos sin una jubilación o pensión (DGEEC, 2018). Esta realidad pone de manifiesto que, aun siendo un país productor de alimentos para 70 millones de personas, cerca de 700.000 paraguayos y paraguayas no tienen asegurado su derecho a la ingesta de 3 comidas diarias (OHCHR, 2016).

Una de las formas de explicar el insatisfactorio desempeño del país, considerando los indicadores básicos de Desarrollo Humano en las áreas de Educación, Salud y Seguridad Alimentaria, es analizando las acciones del Estado paraguayo, sus instituciones y sus políticas sociales, las cuales, a decir de Mkandawire son el resultado de complejos procesos de negociaciones y conflictos sociales, políticos y económicos, en que se conquistan y deciden las áreas de intervención del sector público (a través de la provisión de bienes, servicios o regulaciones), en búsqueda del bienestar general. Con especial énfasis, para comprender las políticas sociales en contextos de desarrollo, deben analizarse con las coyunturas políticas, de las cuales se formulan y se implementan dichas políticas (2001).

Tomando en cuenta lo expuesto, este artículo tiene como finalidad contribuir al área de políticas sociales en Paraguay, considerando 
la caracterización de los Estados/Regímenes de Bienestar y al Estado Paraguayo como unidad de análisis en los que se resalta su fuerte vínculo con el clientelismo político en su formación y expansión; así también se revisan cómo estos conceptos se materializan en la evolución de la institucionalidad de las políticas sociales, sus características y las principales estrategias, programas y proyectos emblemáticos que fueron implementándose a lo largo de estas tres décadas de transición democrática inconclusa.

En este sentido, para darle una mayor precisión a lo que se pretende examinar, se divide el análisis en 3 etapas bien diferenciadas entre sí:

a) 1989 - 2003, la fase inicial o desarrollo incipiente del accionar estatal a los efectos de garantizar la provisión de un estándar mínimo de bienestar para su población.

b) 2003 - 2013, cuando se inician los programas de lucha contra la pobreza, se da el afianzamiento de los derechos sociales constitucionales mediante la consolidación y ampliación de los principales programas e instituciones abocadas a contribuir con el bienestar de la población, con mayor énfasis en la que está en situación de vulnerabilidad.

c) 2013 - 2018, se da una ruptura con lo conformado en la década anterior, buscando reconfigurar la gestión estatal en materia de políticas sociales, dándole un rol más residual al Estado y mayor participación al mercado y/o a la familia, como principales proveedores de bienestar de la población. 


\section{Definiendo el estado, elementos y clasificación: estados de bienestar o régimen de estados de bienestar}

Primeramente, es fundamental definir la unidad de análisis, "el Estado", su concepto y elementos principales. Abente parte de la conceptualización, diferenciando sus dos características predominantes: el Estado como aparato (como institución burocrática) y como la encarnación articulada de relaciones sociales (2012).

Al estudiar al Estado como aparato, se identifican sus características clásicas webberianas y sus atributos más modernos: comunidad humana que posee el monopolio de la violencia legítima, que ejerce en un determinado territorio, centralizado y autónomo. Esto se relaciona con el poder político ejercido por un conjunto de instituciones (con reglas, roles y recursos), que operan bajo un marco constitucional (reglas), que poseen determinadas funciones (roles) y con determinados recursos para el financiamiento de sus actividades. En términos de Fukuyama, se habla de alcance (según sus funciones: Estado Mínimo, Estado Subsidiario y Estado Desarrollista), y de fuerza (capacidad de cumplir dichas funciones: Defensa y Seguridad, Fiscalidad, Capacidad de la burocracia estatal) (2004).

Tomando como foco de análisis al Estado, como entidad articuladora de las relaciones sociales, donde éste "encarna y aglutina la identidad colectiva y se constituye en la instancia pública por excelencia que se sitúa más allá de los intereses creados de grupos particulares y por ende arbitra (o no) políticas y cursos de acción por sobre los conflictos e intereses sociales" (Ibid, 58). Los elementos principales de esta postura son seguridad social y protección contra el desempleo, la lucha contra la pobreza y legitimidad fiscal. 
Profundizando más, es importante para la discusión planteada la definición del "Estado de Bienestar" que Esping-Andersen propuso en su estudio "The Three Worlds of Welfare Capitalism" (1990), como uno de los pioneros en elaborar una tipología para clasificar a los Estados desarrollados capitalistas, según el "tipo de bienestar" que despliegan a favor de su población. Este sociólogo argumenta que en el nivel más general existe una matriz institucional en la que: el Mercado, Estado y Familia, son los responsables de proveer a la población en general los "resultados de bienestar". Cada Estado de Bienestar adopta diferentes formas de organización, los cuales no están, por lo tanto, distribuidas linealmente, sino agrupadas por tipos de Estado.

La clasificación de los Estados de Bienestar según análisis socioeconómicos y políticos de los países pertenecientes al bloque de la $\mathrm{OCDE}^{3}$ y los arreglos institucionales, las reglas y acuerdos que guían y dan forma a las decisiones sobre la política social, el incremento o recorte de gastos fiscales, la calidad de los beneficios o servicios y sus criterios de elegibilidad, definiciones de los problemas sociales e incluso la estructura de respuesta y demanda de los gobiernos, tuvo como resultado tres tipos de Estado de Bienestar:

a) El residual o liberal: el mercado es el agente primario de distribución de los resultados de bienestar y solamente el Estado actúa cuando falla el mercado o las familias son incapaces de proporcionar dichos outcomes a los individuos.

b) El corporativo-conservador: donde existen sistemas altamente contributivos dependientes de las redes familiares, estratificados según los tipos de empleos, se

${ }^{3}$ Organización para la Cooperación y el Desarrollo Económico (OCDE) 
reciben los beneficios, el Estado juega un papel de socio y regulador de la distribución.

c) El socialdemócrata o universal: se basa en principios de justicia social y el Estado busca "de-comodificar" y "desfamiliarizar" ${ }^{5}$ " para el usufructo y goce de los derechos sociales básicos como la salud, educación, vivienda, protección social.

Uno de los puntos clave de este análisis, que atañe a los objetivos de este artículo, es el que Esping-Andersen (1990) menciona como "un hecho histórico que precede a la construcción del Estado del bienestar ha dependido de la formación de coaliciones políticas. La estructura de las coaliciones políticas es mucho más decisiva que los grados de poder de cualquier clase individual". Si bien cada tipo de Estado de Bienestar tiene orígenes diferentes, según los contextos históricos-políticos, una coalición nacional de varias clases ${ }^{6}$ (sectores industrial-urbano y productores rurales), que cuenten con una fuerte noción de solidaridad entre clases, es una de las piedras angulares del nacimiento y consolidación de los Welfare States en el norte global.

Esta definición y clasificación de los tipos de estados de bienestar han sido ampliamente debatidas y criticadas desde el mundo en vías de desarrollo, donde la tipología de Estados de Bienestar (liberal-residual, conservador-corporativista y socialdemócrata) no encajan con el diverso contexto social, político y económico de los países periféricos. Gough y Wood (s/f) han reformulado la matriz institucional de distribución del bienestar en una forma más

\footnotetext{
${ }^{4}$ Ocurre cuando un bien o servicio se accede como una cuestión de derecho, y cuando una persona puede mantener su sustento sin depender del mercado

${ }^{5}$ Mismo concepto, pero esta vez referido a la independencia de la familia como proveedor de dicho bien o servicio

${ }^{6}$ en inglés cross-class coalition
} 
amplia, al agregar un jugador más al triángulo compuesto por Estado, Mercado y Familia: la comunidad (2004).

Por "comunidad" se entiende, para países del continente africano o el sudeste asiático, las relaciones tribales o étnicas que moldean y configuran las reglas de acceso, distribución y permanencia de los individuos dentro del espectro de las políticas públicas. Para nuestra realidad latinoamericana (y por sobre todo paraguaya), la "comunidad" representa la afiliación política-partidaria (Rojas, 2018a).

Otro aporte importante es la conversión de la unidad de análisis de los Estados de Bienestar a los Regímenes de Bienestar, haciendo una exploración más amplia, no solo centrada en los arreglos institucionales, sino también expandiéndola a todo el conjunto de políticas y prácticas que afectan los resultados de bienestar y los efectos de estratificación en diversos contextos

73 sociales y culturales. También, se debe tener en cuenta, los sistemas informales de provisión social y la diferente naturaleza de los regímenes políticos.

Fruto de este análisis, se generaron tres categorías para los países en vías de desarrollo:

a) Regímenes de estado de bienestar: Entendidos como el conjunto de condiciones en las que las personas pueden razonablemente esperar satisfacer (en mayor o menor medida) sus necesidades de seguridad a través de la participación en los mercados laborales, los mercados financieros y la función de financiamiento y aprovisionamiento de un "Estado de Bienestar" semejante a los de la OCDE. Este tipo de régimen requiere del desarrollo de economías capitalistas, donde los mercados laborales son altamente formales, los Estados 
relativamente autónomos y las instituciones democráticas bien arraigadas.

b) Régimen de seguridad informal: Aquí se refleja un conjunto de condiciones en las que las personas dependen en gran medida de las relaciones comunitarias y del capital social familiar para satisfacer sus necesidades de seguridad, en su sentido amplio. Estas relaciones suelen ser jerárquicas y asimétricas. Esto resulta en una inclusión problemática o incorporación adversa, por lo que las personas más pobres intercambian cierta seguridad a corto plazo a cambio de una vulnerabilidad y dependencia a largo plazo. Las relaciones subyacentes entre patrón-cliente se refuerzan y pueden ser extremadamente resistentes a las presiones de la sociedad civil para reformarlas y a las políticas emanadas a lo largo de las líneas programáticas del Estado de Bienestar. Sin embargo, estas relaciones comprenden una serie de derechos informales y permiten un cierto grado de seguridad informal (Wood, 2004).

c) Regímenes de inseguridad: conceptualización, que refleja las condiciones típicas de estados fallidos o de los estados depredadores, donde prevalece la inseguridad y en los que la presencia de actores externos poderosos interactúan con actores internos débiles para generar conflicto e inestabilidad política. Los gobiernos nacionales no pueden desempeñar ni siquiera un papel de gobernanza potencial ni de mejora de la seguridad. El resultado es un círculo vicioso de inseguridad, vulnerabilidad y sufrimiento para todos menos para una pequeña élite, y sus ejecutores y clientes.

Observando las características descriptas y los objetivos de este artículo, el Paraguay encaja en el régimen de seguridad informal. 
Por lo tanto, en el siguiente apartado se describe al Estado paraguayo en el marco del Régimen de Seguridad Informal.

\section{Estado paraguayo, conformación histórica y captura clientelar}

El estado paraguayo ha sido estudiado desde diferentes ópticas. A través de las perspectivas de la academia y de los organismos multilaterales, se ha repasado su funcionamiento macro y sus necesidades de reforma (OECD, 2018; BM, 2018; IIGC, 2003); otros estudios han remarcado cómo su performance genera incidencias negativas en la calidad de la democracia (Abente y Masi, 2005; Abente, 2007), y han analizado su desempeño dual en lo económico y social (Morley y Vos, 1997).

75 Este artículo busca ser un aporte científico sobre el estado paraguayo, tratando de caracterizarlo dentro de la tipología de regímenes de estados de bienestar e intentar explicar su formación y desarrollo, así como también obtener una revisión en prospectiva del deber ser, para encaminar las políticas sociales hacia el régimen de bienestar.

En ese contexto, a lo largo de la historia paraguaya, se reconoce la extensa tradición de liderazgos personalistas y caudillistas. Desde su origen como nación independiente, los partidos políticos tradicionales (Asociación Nacional Republicana, Partido ColoradoANR y Partido Liberal Radical Auténtico - PLRA, fundados en 1887), ambos, a decir de Nichols (1969), más que desempeñarse como partidos políticos, funcionaron como asociaciones o grupos de karaies $^{7}$, de propietarios o dueños de tierras que ejercían el poder absoluto, tanto de sus terrenos como de los vasallos

${ }^{7}$ En guaraní Señores, con muchas similitudes a los señores feudales de la edad medieval 
quienes vivían en ellos, ahora convertidos en partidarios, a quienes se los consideraba parte de su propiedad y les debían obediencia y que, a cambio, eran objeto de su protección y benevolencia.

Las intensas disputas, tanto internas como entre los partidos tradicionales, incluidas una guerra civil (1947), dieron paso, en 1954, a una de las dictaduras militares más largas de la historia latinoamericana: el régimen de Alfredo Stroeessner, quien gobernó ininterrumpidamente hasta 1989 con la tribología Gobierno, Fuerzas Armadas (FFAA) y ANR. No solo domesticó y cooptó todo intento de compartir el poder, sino que, a decir de Setrini (2010), dio forma a una configuración de la sociedad paraguaya en 3 clases bien definidas:

a) La élite, con la que la aristocracia tradicional paraguaya compartió espacios con "la nueva élite" conformada por los fieles dirigentes civiles de la ANR y FFAA, quienes ejercían el control del Estado, las empresas públicas y obtenían los permisos para la explotación de negocios, tanto legales como ilegales, y los contratos estatales.

b) Nueva clase media urbana: integrada por funcionarios públicos ${ }^{8}$ y profesionales independientes.

c) Campesinado: conformaron la base de apoyo popular al régimen ${ }^{9}$ y a cambio recibieron asistencia técnica, crediticia, tierras, subsidios y precios preferenciales de sus principales productos.

\footnotetext{
${ }^{8}$ Requisito indispensable para ingresar a la función pública, fuerzas armadas/policiales ser afiliado al Partido Colorado (Setrini 2010:p.23)

${ }^{9}$ Para 1950, la población de Paraguay era $65 \%$ rural, el sector agrícola tenia un importante peso en la economía (48,9\%), mientras que el $55 \%$ de su población estaba empleada en actividades agrícolas, principalmente de subsistencia (ibid:p.17)
} 
A pesar de la llegada de la Democracia (1989), de una nueva Constitución Nacional (1992), y de las primeras elecciones libres, el legado del stronissmo marcó huellas profundas en el sistema político paraguayo, y dejó, como una de sus herencias más importantes, la institucionalización del clientelismo y el patronazgo, definida en términos de privatización del Estado paraguayo, según Nickson y Lambert (2002). Esta nefasta práctica fue aggiornada a los nuevos tiempos democráticos e inclusive perfeccionada por los tradicionales y los nuevos partidos/movimientos políticos que le disputan el control del aparato estatal al histórico Partido Colorado. Todos estos vicios impidieron finalmente al estado paraguayo generar una estructura burocrática sólida y compacta orientada a convertirse en un estado desarrollista (Richards, 2005).

Un análisis profundo de las características históricas y las peculiaridades generadas por el clientelismo paraguayo, las relaciones, expectativas e interacciones entre el estado-sociedad, en la actualidad, se encuentra en la obra Correligionarios Actitudes y prácticas políticas del electorado paraguayo (Lachi y Rojas Scheffer, 2018).

En dicha obra, además de caracterizar la rigidez del sistema político-electoral paraguayo, se exponen dos razones principales del clientelismo paraguayo: por el lado de la "demanda", se mencionan las necesidades socioeconómicas reales (ibid,142147; Rojas, 2018b) y por el lado de la "oferta", se expresan fenómenos culturales conocidos como "la ética del orékuete ${ }^{10 "}$ (Morínigo, 2005).

\footnotetext{
${ }^{10}$ En la lengua guaraní hay dos formas de decir nosotros: "ñandé", término con el que se expresa de manera amplia e incluyente a la persona que habla de sí misma más y de otra u otras personas; y "oré", que es un nosotros excluyente, que limita el nosotros a un grupo, secta o tribu específicos, y el "orekueté", por su parte, hace relación a una radicalización
} 
Con relación a la conformación, mantenimiento y consolidación del Régimen de Seguridad Informal del Paraguay, es importante analizar cómo sus causas y consecuencias se retroalimentan y refuerzan.

Por un lado, las acciones del Estado paraguayo generan barreras, inequidades e ineficiencias para gran parte de la sociedad paraguaya, en lo que respecta al acceso a bienes, servicios y regulaciones a favor del bienestar social. Por otro lado, con la rigidez del sistema político-electoral, sus principales actores, la ANR y el PLRA, no cuentan con los incentivos necesarios para obrar, ejercer el poder a favor de la mayoría, ya que existe una magra (o nula) necesidad de rendición de cuentas (accountability), debido a que gran parte del electorado es propenso a votar a favor de su partido, sin importar el perfil del candidato o sus propuestas electorales.

En otras palabras, el factor por el cual, el candidato de turno será evaluado por sus potenciales electores es por su grado de reciprocidad o voluntad de retribuir el apoyo electoral otorgado, en prebendas o favores clientelares, una vez elegido, a favor de sus correligionarios, y no por su gestión pública eficiente y transparente.

En el siguiente apartado, se analizan los 30 años de vida en democracia, se revisan los conceptos expuestos hasta aquí y cómo se configura y conduce la gestión estatal en materia social, identificando, sus principales características, institucionalidad y contextos sociales, políticos y económicos presentados. Teniendo en cuenta esas características se han identificado en 3 etapas, según su trayectoria.

del esquema oré, traslada al plano político la praxis del "orekueté", es decir los intereses grupales por encima de los intereses colectivos (Morínigo 2005) 


\section{Fase inicial 1989-2003.}

Contexto social-político-económico

La caída de la larga dictadura de Stroessner (1954-1989) y la llegada de la democracia permitieron a los movimientos sociales tradicionales (sindicales, campesinos y obreros) recuperar la libertad de reclamar sus demandas postergadas. También, nuevos colectivos (estudiantes secundarios, universitarios, familias sintecho, grupos pro-igualdad de género, entre otros) se sumaron a las manifestaciones en pos de exigir derechos y garantías estatales para alcanzar un mínimo de bienestar social.

La llegada de la democracia también hizo palpable la otra realidad que ocultaba el lema "paz y progreso": El Estado paraguayo comenzó a medir estadísticamente el bienestar de su población. El resultado de la radiografía presentó un país con niveles de

79 subdesarrollo y desigualdad más parecidos a países centroamericanos que a sus pares del cono sur. La pobreza y la desigualdad comenzaron a ser reconocidas como un problema a afrontar por parte del Estado (Rivarola, 2018).

Los índices de pobreza, en esta primera etapa, muestran que, la población en condición de pobreza monetaria estaba por encima del $50 \%$, y la economía nacional estaba atravesando por un periodo de recesión, lo cual podía estar dificultando garantizar las condiciones de bienestar para las personas en Paraguay.

La situación económica heredaba una alta deuda pública. Las primeras medidas económicas tomadas (medidas de austeridad fiscal y eliminación de los sistemas de cambio múltiples y la liberalización de las tasas de interés del sistema financiero nacional) tuvieron efectos positivos, al inicio, pero luego produjeron severas crisis financieras y graves consecuencias económicas, que se sintieron hasta largo tiempo después. En ese 
periodo específico, el crecimiento promedio de la economía fue de aproximadamente $1,5 \%$; el más bajo del periodo democrático (DENDE, 2015). En el siguiente gráfico, se presenta la evolución de las tasas de pobreza monetaria y del Producto interno bruto del periodo analizado.

Gráfico N$^{\circ}$ 1: Evolución de la pobreza monetaria y del PIB. Primer periodo de análisis

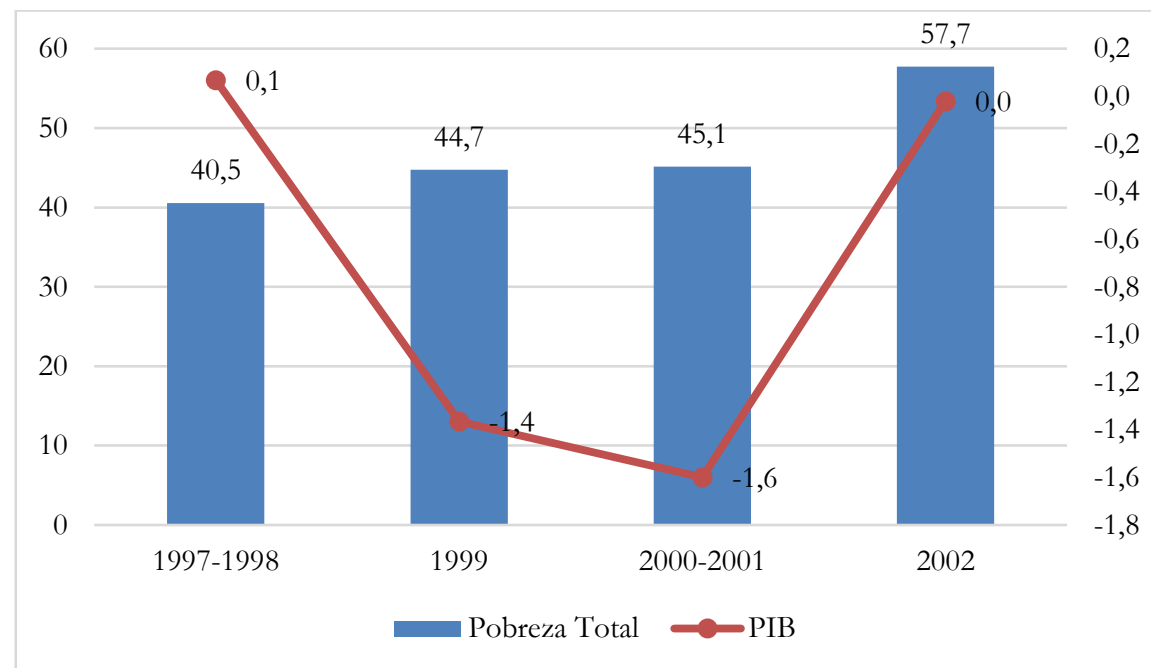

Fuente: Elaborado con datos de los principales indicadores de pobreza de la población, por año de encuesta (DGEEC, s/f), y del Anexo Estadístico de Cuentas Nacionales (BCP, 2020).

El contexto político tampoco fue el mejor, ya que la democracia paraguaya sufrió las disputas políticas internas de la ANR, partido de gobierno que continuó con las riendas del país, esta vez por la vía del voto democrático. Tras largos años de poder centralizado y equilibrado entre miembros de un mismo partido, con la repentina ausencia del poder central, se atomizaron y se avivaron fuertes luchas internas que devinieron en una sucesión de intentos de 
golpe de Estado y crisis de gobernabilidad sucesivas ${ }^{11}$, un vicepresidente asesinado, una revuelta popular, tres ciclos parlamentarios y cuatro presidentes durante los primeros catorce años de vida democrática.

En este periodo, a la fuerte crisis de gobernabilidad y al estancamiento económico, se sumó la continua incapacidad del Estado paraguayo para responder a las demandas ciudadanas. Para analistas internacionales, Paraguay era considerado un país capaz de generar efectos desestabilizadores en la región sudamericana, en cuestiones de seguridad, debido a la porosidad de sus fronteras, la corrupción rampante y la debilidad de sus instituciones, acuñándose el termino de Estado en Proceso de Falla (Sampó, 2007).

\section{Evolución de la institucionalidad social 1989-2003}

La Constitución Nacional de 1992 sancionó importantes innovaciones sobre los derechos, deberes y garantías para la población paraguaya. Específicamente, el estado reconoce su rol principal como promotor de la calidad de vida para todos, como menciona el artículo 6to. En los artículos siguientes, se establecen/reafirman los derechos universales de la salud (art. 68), educación (arts. 73 y 76), del derecho al trabajo y la promoción del pleno empleo (arts. 86 y 87), y lo concerniente al Sistema de Seguridad Social obligatorio e integral (art. 95).

Paralelamente, la nueva Constitución Nacional trajo consigo la creación de nuevas dependencias del Poder Ejecutivo, particularmente Secretarías, surgidas con el fin de atender determinadas áreas de las políticas públicas, largamente

${ }^{11} \mathrm{https}: / / w w w . b b c . c o m / m u n d o /$ noticias/2013/02/130203_lino_oviedo_paraguay_perfil_jgc 
postergadas durante la dictadura. En ese mismo orden, las sucesivas conferencias-cumbres de las Naciones Unidas, realizadas a finales del S.XX, a los efectos de consensuar marcos conjuntos para políticas públicas sobre intereses compartidos, arrojaron como resultado compromisos internacionales asumidos que devinieron posteriormente en la creación de organismos especializados para atender segmentos específicos de la población: Mujer, Niñez y Adolescencia y Acción Social (Serafini y Zavattiero, 2018).

En la siguiente tabla, se puede apreciar la evolución de la institucionalidad en materia de políticas sociales, desde la época pre-1989 hasta el fin de la primera fase 2003.

Tabla $\mathbf{N}^{\circ}$ 1: Evolución de la institucionalidad social. Periodos pre1989 y 1989 hasta 2003

\begin{tabular}{|l|l|l|}
\hline Periodo & Año & Institución \\
\hline \multirow{4}{*}{$\begin{array}{l}\text { Antes de } \\
\end{array}$} & 1909 & Ministerio de Hacienda ${ }^{12}$ \\
\cline { 2 - 3 } & 1936 & $\begin{array}{l}\text { Ministerio de Salud Pública y Bienestar } \\
\text { Social'13 }\end{array}$ \\
\cline { 2 - 3 } & 1943 & Ministerio de Educación y Ciencias $^{14}$ \\
\cline { 2 - 3 } & & Instituto de Previsión Social \\
\cline { 2 - 3 } & 1948 & Ministerio de Justicia y Trabajo \\
\hline & 1951 & Instituto de Reforma Agraria ${ }^{15}$ \\
\hline & 1962 & Secretaría Técnica de Planificación \\
\cline { 2 - 3 } & 1975 & Instituto Paraguayo del Indígena \\
\hline
\end{tabular}

\footnotetext{
${ }^{12} \mathrm{Si}$ bien sus orígenes datan de la época de la independencia (1811), fue en el año de la creación del fondo de jubilaciones y pensiones para el personal del sector público, actual Caja Fiscal, que se dio la ley de Organización Administrativa (1909).

${ }^{13}$ Su primer nombre fue Ministerio de Salud Pública (Decreto 2000/36)

${ }^{14}$ Su primer nombre fue Ministerio de Educación (Decreto 19392/43)

${ }^{15}$ El Instituto de Reforma Agraria, luego renombrado Instituto de Bienestar Rural (1963), fue el predecesor del actual INDERT (reformado en 2004)
} 


\begin{tabular}{|c|c|c|}
\hline \multirow{6}{*}{$\begin{array}{l}\text { Después } \\
\text { de } 1989\end{array}$} & 1989 & Dirección de Beneficencia y Ayuda Social \\
\hline & 1991 & Consejo Nacional de la Vivienda ${ }^{16}$ \\
\hline & 1992 & Secretaría de la Mujer \\
\hline & 1993 & $\begin{array}{l}\text { Secretaría de Desarrollo para Repatriados } \\
\text { y Refugiados Connacionales }\end{array}$ \\
\hline & 1995 & Secretaría de Acción Social \\
\hline & 2001 & $\begin{array}{l}\text { Secretaría Nacional de la Niñez y la } \\
\text { Adolescencia }\end{array}$ \\
\hline
\end{tabular}

Fuente: Elaboración propia a partir de las páginas web institucionales, Serafini \& Zavattiero (2018), PIEPE (2010).

\section{Contexto de las políticas sociales 1989-2003}

La irrupción de la problemática social dentro de un contexto de 83 una economía en recesión e instituciones débiles y politizadas, trajo consigo intervenciones estatales con fuerte sesgo paternalista y de carácter de beneficencia. La constante crisis de gobernabilidad y legitimidad política (específicamente en el último periodo de gobierno), hizo que las respuestas dadas por los sucesivos gobiernos de esta primera fase incipiente fuera a través de acciones focalizadas hacia el sector vulnerable, basadas principalmente en fragmentados subsidios directos (monetarios y/o en especies), distribuidos mayoritariamente en los grandes centros urbanos, con limitados presupuestos y escasa articulación interinstitucional entre las nuevas y antiguas entidades de carácter social creadas (Duarte-Recalde, 2018).

Barrios es tajante al calificar la década de los 90's como uno de “...los periodos históricos de mayor ineficacia de la acción estatal

\footnotetext{
${ }^{16}$ La Comisión Nacional de la Vivienda fue refundada con el nombre de Secretaria Nacional de la Vivienda y el Hábitat (2010) actualmente Ministerio de Urbanismo, Vivienda y Hábitat.
} 
en el país" (2005). Paralelamente, en uno de los diagnósticos sectoriales disponibles en el PEES (2009), se utiliza el termino de "involución institucional" para calificar el proceso paulatino y persistente de deterioro de las capacidades de gestión administrativa y de liderazgo, además de la pérdida de recursos humanos por parte de las instituciones públicas durante la década del 1990.

En ese mismo orden, Galeano califica la gestión de las políticas sociales como negativo en el balance final. $\mathrm{Ni}$ en las intervenciones urbanas (vivienda, agua y saneamiento, expansión del trabajo digno) ni en las rurales (el acceso a tierras, mercado para la producción nacional, acceso a créditos/refinanciamiento) tuvieron su efecto esperado (2005). Los principales déficits radicaron en la inadecuada comprensión y análisis del fenómeno de la pobreza paraguaya (con mayor acentuación en las zonas rurales), lo cual conllevó al diseño equivocado de programas y proyectos que no cuajaban con las realidades y necesidades de la población, la cual se vio empobrecida día a día, llegando la pobreza a afectar a casi la mitad de la población para el inicio de la siguiente fase, como veremos a continuación.

\section{Crisis, consolidación y visión hacia el régimen de bienestar 2003-2013}

Nicanor Duarte Frutos (2003 - 2008) asume en medio de una profunda crisis social, institucional e inestabilidad económica, con altos niveles de pobreza, desempleo, déficit fiscal y atraso en el pago de la deuda externa (default selectivo). Políticamente, fue la segunda peor elección de la ANR desde la vuelta a la democracia, 
con un magro $37.1 \%$ de votos ${ }^{17}$, con una minoría en senadores y en diputados que lo obligó a tener que esgrimir sus habilidades de negociación con la oposición, si bien fragmentada pero afín en términos ideológicos con la ANR, lo cual le dio cierta estabilidad y gobernabilidad.

Con poco margen para maniobrar, el primer presidente electo después de la apertura política de 1989 que no formó parte del entorno stronista, decide nombrar un gabinete de gobierno mixto, con parte de los ministros que respondieron al ala dura del coloradismo y otra integrada por gente alejada (e inclusive crítica) del ámbito político, más bien proveniente de la academia o del sector de las cooperativas menonitas del norte del país, nombres recibidos con beneplácito por sectores democráticos (Bareiro, 2003).

La gestión de Duarte Frutos buscó enfocarse en la transparencia, 85 gobernabilidad, con miras a generar desarrollo equitativo y mejorar la gestión del sector público. Para ello implementó reformas en la administración estatal: promulgó la Ley de Reordenamiento Administrativo y Adecuación Fiscal, reformó la banca pública, Dirección de Aduanas, las Cajas Fiscales y creó la Agencia Financiera de Desarrollo (AFD), la Dirección General de Contrataciones Públicas (DNCP). Así también introdujo cambios para modernizar y jerarquizar el Ministerio de Hacienda, a los efectos de aumentar la transparencia, la eficiencia, el nivel de cumplimiento tributario y aumentar los ingresos fiscales, firmó acuerdos importantes con el sector privado y la sociedad civil que le dieron el apoyo necesario para encarar dichas reformas (Borda 2007).

\footnotetext{
${ }^{17}$ En la siguiente elección abril 2008-2013 sería derrotado por Fernando Lugo cosechando un histórico $30,63 \%$ versus $40.9 \%$ de la Alianza Patriótica para el Cambio (TSJE s/d)
} 
El desgaste político de años de administrar el Estado por parte de la ANR, sumado a el despertar de los movimientos sociales y la gran alianza conformada por los atomizados partidos y movimientos de izquierda y centroizquierda, con el centenario PLRA, dieron el marco para la alternancia democrática, de la mano del ex obispo Fernando Lugo, luego de 60 años de hegemonía colorada, el 20 de abril de 2008.

A pesar de la debilidad política e incoherencia ideológica, al interior de la Alianza Patriótica para el Cambio (APC), el gobierno de Fernando Lugo intentó continuar e intensificar las reformas iniciadas en el periodo anterior. Según consta en el Plan Estratégico, Económico y Social (PEES), se consideraba la necesidad de "impulsar el desarrollo con igualdad de oportunidades para todos y todas, con crecimiento económico sustentable y sostenido para cambiar el rumbo, el ritmo y la calidad del crecimiento" (2008).

Para ello se continuó con el fortalecimiento de las instituciones estatales, mejora de la eficacia de las políticas públicas, diversificación productiva, preservación del medio ambiente y mejor aprovechamiento de los recursos energéticos, participación de la sociedad civil y del sector privado en la economía, fortalecimiento de las micro y pequeñas empresas, aumento de su capacidad competitiva, armonización y coordinación de las acciones del gobierno para apoyar el desarrollo regional descentralizado (Rojas Viñales, 2018).

En esta segunda etapa, la economía paraguaya iba mejorando notablemente, aunque se dieron altibajos importantes al final de este periodo. Los niveles de pobreza monetaria, por su parte, iban disminuyendo, si bien no hay una relación directa, podía estar coadyuvando a la mejora de las condiciones de vida de la población y a la mejora de los indicadores de pobreza monetaria. 
En el siguiente gráfico, se aprecia la disminución de $23.4 \%$ en el indicador de pobreza monetaria total y un crecimiento del PIB promedio de $4,6 \%$ del PIB correspondiente a esta etapa.

Gráfico N²: Evolución de la pobreza monetaria y del PIB. Segundo periodo de análisis 2003-2013

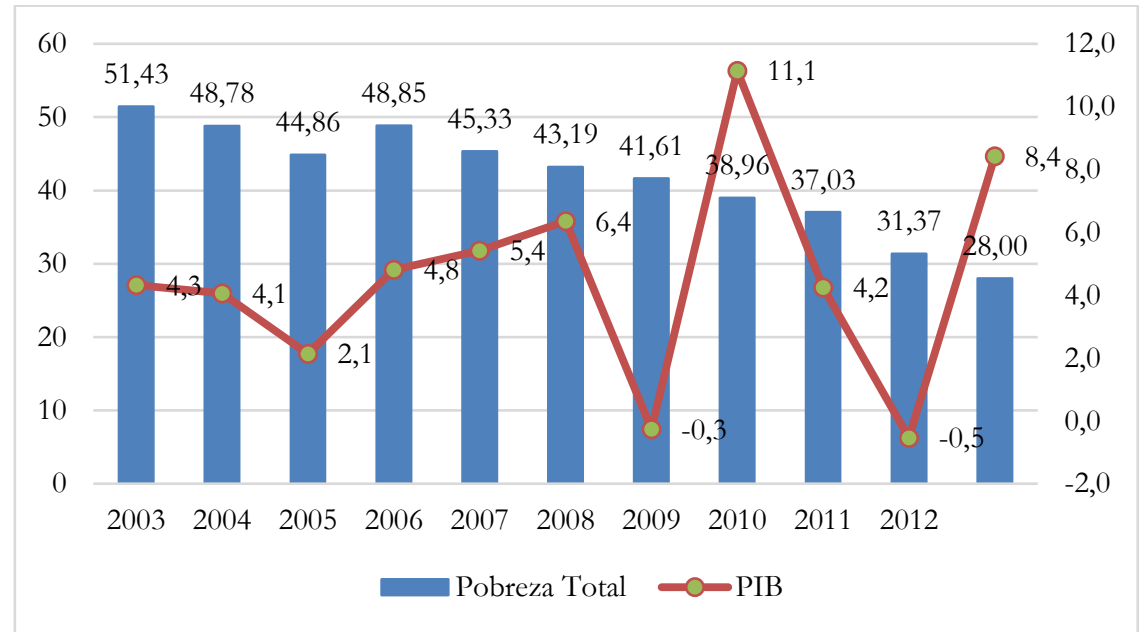

Fuente: Elaborado con datos de los principales indicadores de pobreza de la población por año de encuesta (DGEEC) y del Anexo Estadístico de Cuentas Nacionales (BCP, 2020).

\section{El nuevo contexto de las políticas sociales 2003-2013}

Este periodo 2003-2013 fue marcado por un contexto regional político favorable hacia el fortalecimiento del papel del Estado en materia social. Se caracterizó por revertir las tendencias de políticas públicas centradas en el mercado, la llamada "ola progresista" o "giro a la izquierda" que se sucedió cuasi en simultaneo en Venezuela, Brasil, Chile, Argentina, Uruguay, Bolivia, Ecuador con el inicio del siglo XXI. Este movimiento tuvo como resultado el incremento de los intercambios de cooperación sur-sur y la creación de la Unión de Naciones Suramericanas 
(UNASUR) (Uribe Gómez, 2018). Paraguay no estuvo al margen de la corriente, de manera pragmática el gobierno de Duarte Frutos, con mayor ímpetu el gobierno de Lugo, se acomodaron al nuevo contexto regional.

Otro hito internacional no menos importante, que sirvió como un marco orientador de las políticas sociales en Paraguay fue la declaración de los Objetivos de Desarrollo del Milenio (ODM) $2000-2015^{18}$. Teniendo como base los 8 ODM, con sus metas e indicadores, permitió el deseño de los dos primeros programas gubernamentales enfocados a combatir la pobreza y la exclusión que afectaban a gran parte de la población paraguaya.

Al respecto, Rojas (2017) expresa que, con el apoyo de las agencias de cooperación multilateral como la ONU y el Banco Mundial, el Estado Paraguayo toma como una de sus banderas más importantes la lucha contra la pobreza y la desigualdad, razón por la cual se diseñan y promulgan documentos estratégicos que guiarán las políticas sociales de los gobiernos de este ciclo.

\section{ENALP (Estrategia Nacional de Lucha contra la Pobreza) 2003-2008 ${ }^{19}$}

Es el documento pionero que sirve como una guía básica para coordinar las acciones del Estado paraguayo para cumplir con las prioridades nacionales y los compromisos internacionales, a fin de permitir la optimización de los recursos destinados a reducir la

${ }^{18}$ Constituyen una síntesis de los compromisos clave de las Cumbres y Conferencias mundiales, llevadas a cabo por el Sistema de NNUU, durante la década de los 90, y fueron acordados en la Cumbre del Milenio, el 8 de septiembre del 2000

${ }^{19}$ Originalmente concebida con el nombre de Estrategia Nacional de Reducción de la Pobreza, Desigualdad y Exclusión Social (ENREPD), se reconfiguró en 2006 finalmente como ENALP (Serafini y Zavattiero, 2018) 
pobreza y la desigualdad. Se crea la figura del Gabinete Social, como espacio para la coordinación de las intervenciones públicas, coordinado por el DIPLANP (Dirección del Plan para la Estrategia Nacional de Lucha contra la Pobreza y la Exclusión Social).

Dentro del ENALP se plantea la conceptualización de la pobreza como "un fenómeno multidimensional expresado básicamente en términos de privación de necesidades básicas (alimentación, salud, educación, agua potable, servicios de salud y energía, ropa, etc.), debido a la falta de ingresos o capacidad o de bienes materiales y sociales" (GS, 2006). Las acciones del Estado paraguayo se dividieron en tres ejes principales: a) Protección social (incluidas aquí las primeras experiencias de transferencias monetarias condicionada ${ }^{20}$ ), b) Promoción social (acciones orientadas a fortalecer el capital social y la participación), y c) Inclusión económica (integración de los individuos al mercado capitalista de trabajo).

La universalidad del acceso a los servicios sociales iba ganando importancia en el debate nacional, a la par que se hacían cada vez más necesarias las políticas sociales focalizadas para enfrentar condiciones y problemas particulares de las poblaciones más pobres y vulnerables. El gobierno de Duarte Frutos fue un parteaguas en la política social, porque se ampliaron las responsabilidades estatales en la atención a las necesidades y demandas sociales. Las reformas reposicionaron al Estado ante la población en condiciones de pobreza, vulnerabilidad y desigualdad (Rojas Viñales, 2018) .

A pesar de la alternancia, o gracias a ella, el giro de la gestión estatal en materia de políticas sociales tuvo un mayor énfasis

\footnotetext{
${ }^{20}$ Tekoporã (En Guaraní Bienestar), Programa Abrazo destinado a familias con niños en situación de calle/trabajo infantil.
} 
durante el siguiente periodo 2008-2012 21 . Como principal eje de acción se estableció el apuntalamiento de la condición de ciudadanía para el ejercicio de los derechos sociales, contraponiéndose a las relaciones patrón-necesidad-cliente tradicionalmente hasta entonces practicadas en Paraguay (Ortiz et al, 2015).

El documento estratégico que orientó el accionar de las políticas sociales fue la Política Pública para el Desarrollo Social 20102020 (PPDS), documento utilizado como base que amplía los conceptos e instrumentos constituidos en el documento ENALP. El PPDS establece un enfoque de desarrollo humano, cultural y social dinámico e inclusivo, que compromete, guía y articula a todas las instituciones que conforman el Gabinete Social (coordinado por una nueva institución, la Unidad Técnica del Gabinete Social).

EI PPDS presentó una visión general que enfatiza el enfoque de derechos y la búsqueda de equidad, a través de la promoción de un modelo de desarrollo que genera cohesión social e inclusión cultural y económica, estableciendo las bases para un futuro Sistema de Protección Social llamado "Sasõ Pyahu". Dentro de este marco, los objetivos nacionales se proponen en tres ejes: calidad de vida para todos, inclusión social y superación de la pobreza y la desigualdad y crecimiento económico sin exclusiones (GS, 2010).

El PPDS fue el marco orientador que permitió acomodar las políticas sociales hacia una trayectoria de fortalecimiento de la universalidad y el enfoque de derechos en el acceso a los servicios, buscando superar la pobreza a través de un sistema articulado de intervenciones públicas, complementando la

\footnotetext{
${ }^{21}$ Si bien debería haber culminado el periodo en el año 2013 fue interrumpido por un golpe parlamentario en junio del 2012, asumiendo el PLRA el resto del mandato
} 
continuidad y ampliación de programas de transferencia monetaria focalizadas como el Tekoporâ y Abrazo. La mayor inversión social que se realizó durante este periodo se manifestó en el diseño y ejecución de programas como las pensiones no contributivas a adultos mayores, la gratuidad de la educación pública hasta la media $^{22}$, del acceso a la salud pública gratuita, a través de la estrategia de atención primaria en salud con las instalaciones de las Unidades de Salud Familiar (USF) y los 11 programas emblemáticos (Rojas Viñales, 2018).

Como resultado del desgaste y fricción constante entre las élites políticas y económicas conservadoras, se consuma, en junio de 2012, un juicio político express que desplaza del poder a Fernando Lugo, asumiendo la presidencia Federico Franco, durante 14 meses. No habiendo mucho tiempo (ni mucha resistencia institucional a la par) para introducir grandes cambios, este periodo cierra con despidos y persecuciones de funcionarios públicos, incorporación de adherentes del PLRA a la función pública, cierre o debilitamiento de programas o unidades afines al sector lugista, dejando el terreno libre para la vuelta al poder del Partido Colorado, tras apenas 5 años de ausencia.

\section{La evolución de la institucionalidad social 2003-2013}

A los efectos de materializar el nuevo paradigma social de este periodo, el estado paraguayo creó nuevas instituciones, elevó de rango, reorientó el andamiaje de otras e incluyó dentro de otras preexistentes nuevas competencias que les permitieran

\footnotetext{
${ }^{22}$ Ley No 4.088/2010 que extiende la gratuidad y obligatoriedad a la Educación Inicial y Media en la educación pública
} 
operatividad a los anhelos expresados, tanto en el ENALP como el PPDS $^{23}$.

Se comenzó con las instancias de coordinación. Históricamente, dicho lugar lo ocupada la Secretaría Técnica de Planificación, (STP) pero, con la conformación del Gabinete Social como espacio político de coordinación de las Políticas, para su dirección, se creó la DIPLANP (2005) y posteriormente la UTGS (2009).

Entre las instancias operativas se creó la Secretaría de Emergencia Nacional (SEN), en el año 2005, para dar respuesta ágil y precisa en los casos de desastre a escala nacional. En el año 2013 se independiza y se institucionaliza la SENADIS, Secretaría Nacional por los Derechos Humanos de las Personas con Discapacidad, se "eleva" de categoría de secretaría a Ministerio de la Mujer, sin que ello represente mayor protagonismo programático ni presupuestario en el quehacer de las políticas sociales nacionales en el 2012.

\section{La ruptura y el retorno 2013-2018}

La breve ausencia del Partido Colorado en el control del poder ejecutivo y el desenlace poco feliz del experimento político opositor en el gobierno permitieron el reagrupamiento y consolidación, bajo un nuevo liderazgo, de la ANR. Si bien, ya tenía coqueteos con el sector político a través de su financiamiento y la participación en la dirigencia de un club de fútbol, Don Horacio Manuel Cartes Jara, un outsider de la política, resulta amplio ganador de las elecciones de abril de 2013, con un contundente $45,83 \%$ de los votos emitidos, y una sorprendente

${ }^{23}$ Es el caso de la Unidad de Economía Social en el Ministerio de Hacienda (2009-2013) 
cuasi mayoría parlamentaria, en ambas cámaras, con 19 senadores (de 45$)$ y 44 diputados (de 80 , una mayoría propia) (TSJE, s/f).

El marco orientador de la gestión de Cartes fue la promulgación del Plan Nacional de Desarrollo Paraguay 2030 (PND), el primero, durante la era democrática, que tenía como objetivo facilitar la coordinación de las acciones del Poder Ejecutivo en los diversos niveles de gobierno. Los ejes de acción para las políticas públicas del PND fueron a) la reducción de la pobreza y el desarrollo social, b) crecimiento económico inclusivo, c) inserción de Paraguay en el mundo, en forma adecuada. Cada eje incorpora dimensiones transversales a) igualdad de oportunidades, b) gestión pública eficiente $y$ transparente, c) ordenamiento territorial $y \quad d)$ sostenibilidad ambiental (Presidencia de la República del Paraguay, 2014).

93 El cartismo se caracterizó, desde el principio, por ser un gobierno de tinte tecnocrático, con un gabinete que sobresalía por la incorporación de técnicos, más que políticos, con un marcado signo neoliberal del direccionamiento de las políticas públicas. En este periodo, se hizo mucho énfasis a la alianza público privada ${ }^{24}$, a través del desarrollo de infraestructura, especialmente vial, la racionalización del gasto público ${ }^{25}$, enfatizándose a la apertura y participación en el mercado internacional, bridando mayores incentivos para la inversión extranjera, manteniéndose la baja tasa impositiva (aspecto congelado desde las reformas tributarias del 2003), favoreciendo a los sectores económicos relacionados a la agroindustria, el comercio y la banca privada (Duarte-Recalde, 2014).

\footnotetext{
${ }^{24}$ Ley 5102/13 de "Promoción de la inversión en infraestructura pública, y ampliación y mejoramiento de los bienes y servicios a cargo del Estado".

25 Ley 5090/13 "De Responsabilidad fiscal"
} 
En este último periodo, se evidencia que la economía transita por una fase de importantes mejoras, a diferencia del contexto latinoamericano. El ritmo de diminución de la tasa de la población en situación de pobreza monetaria se estanca. Disminuye, en este periodo, 3.8\%. Se observa un cuarto de la población total del país bajo la línea de pobreza monetaria. Si bien, el en 2013, la economía paraguaya alcanzó su mayor nivel, en los años siguientes, el crecimiento se mantuvo constante, por encima del $3 \%$, como podemos observar en el gráfico 3.

Gráfico № 3: Evolución de la pobreza monetaria y del PIB. Tercer periodo de análisis

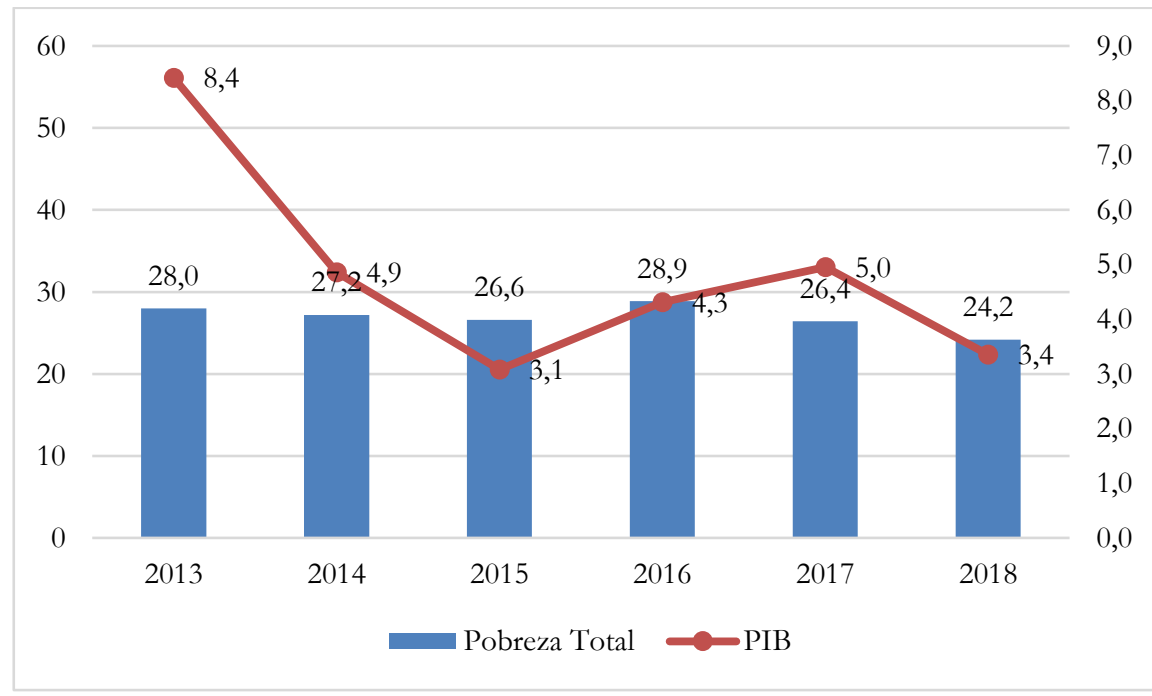

Fuente: Elaborado con datos de los Principales indicadores de pobreza de la población por año de encuesta (DGEEC) y del Anexo Estadístico de Cuentas Nacionales (BCP, 2020). 


\section{Contexto de las políticas sociales 2013-2018}

El gobierno de Cartes significó una ruptura del proceso iniciado en el 2003, dado que la tendencia fue apuntar a una reducción del estado como medio para lograr un bienestar compartido ${ }^{26} \mathrm{y}$ sustituirlo, paulatinamente, por la capacidad de las familias y el mercado como principales proveedores de bienestar. Muestra de ello fue el programa "Sembrando Oportunidades" con el que se encomienda a la Secretaría Técnica de Planificación (STP) la elaboración e implementación del Programa Nacional de Reducción de la Pobreza.

Sembrando Oportunidades tenía como ejes la generación de ingresos (capacitación, asistencia técnica, inserción a cadenas de valor, microcréditos) y el acceso a servicios sociales (concentrando aquí las políticas focalizadas de TMC así como

95 también las de corte universal como salud, educación e identidad). El programa se caracterizó por un restringido perfil de intersectorialidad y una conceptualización de la pobreza como un problema unidimensional de ingreso, con un abordaje de focalización geo-referenciada a través de las "fichas sociales" (Rojas, 2017).

Los logros de la política social de Cartes fueron el incremento de la inversión social, basado principalmente por el aumento de la cobertura de los principales programas de transferencia monetaria condicionada, Tekoporâ y Adultos Mayores, el acceso a viviendas populares, la ampliación de la cobertura de la red de Unidades de Salud de la Familia (USF), el Programa de Alimentación Escolar

\footnotetext{
${ }^{26}$ Aquí se pueden citar el menor o estancamiento en la inversión de los programas emblemáticos del periodo anterior como hogares de acogida ABRAZO y centros para adultos mayores del IBS-MSPSBS, así como la fusión del Programa de Producción de Alimentos PPA en la estructura de la Dirección de Extensión Agraria del Ministerio de Agricultura y Ganadería.
} 
(PAE) y las becas de postgrado en el exterior para paraguayos (BECAL).

\section{La evolución de la institucionalidad social 2003-2013}

La elevación de categoría del antiguo Viceministerio de Trabajo a Ministerio de Trabajo, Empleo y Seguridad Social (MTESS), en el año 2013, ha sido una de las incorporaciones más prometedoras en la institucionalidad social paraguaya, especialmente por la doble misión de generar políticas integrales y velar por el empleo decente, así como ser el ente rector del caótico y excluyente sistema de seguridad social.

Sin embargo, durante este periodo no se pudo contribuir a mejorar los desafíos inherentes a contar con una estructura políticoburocrática que garantice una mejor gestión de las políticas sociales. Por el contrario, tanto a nivel estratégico como operativo, se mantuvieron y profundizaron los solapamientos y duplicaciones en la otorgación de bienes y servicios. En el 2013 se independizó e institucionalizó la Secretaría Nacional de la Juventud (SNJ), sumando una nueva institución que vela por un segmento de la población a través del otorgamiento de subsidios para estudios universitarios (Rojas, 2018b).

\section{Reflexiones finales y desafíos}

Como resumen de este análisis sobre la institucionalización de las políticas sociales en Paraguay y el Régimen de Seguridad Informal, en el siguiente gráfico se presenta la serie completa 1997-2018 que muestra la fluctuante relación entre el crecimiento 
del PIB total y la disminución de la población en situación de pobreza monetaria.

Gráfico № 4: Evolución del PIB y pobreza monetaria total en Paraguay. Años 1997 - 2018.

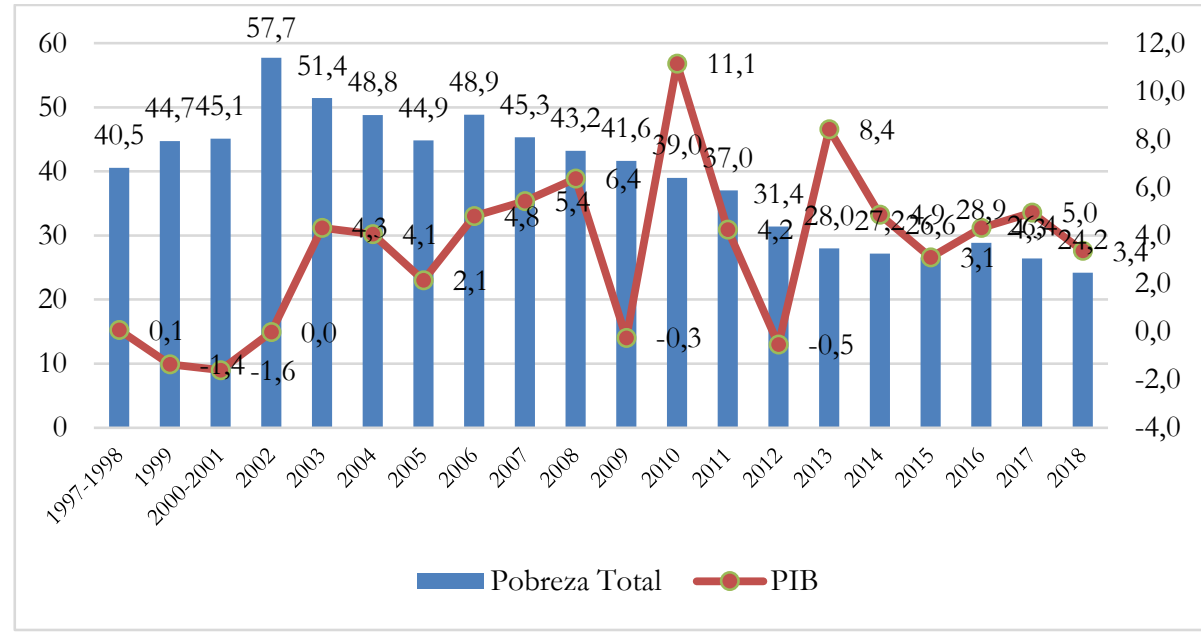

Fuente: Elaborado con datos de los Anexos Estadísticos de Cuentas Nacionales (BCP, 2020).

A lo largo del periodo analizado, se ve que la pobreza en Paraguay, efectivamente, ha disminuido a menos del $50 \%$ de los niveles iniciales, y que la economía ha evolucionado con importantes altibajos, alcanzado su punto máximo en el 2010. La disminución de la pobreza monetaria es el resultado no solo del crecimiento positivo de la economía, sino del fortalecimiento de la institucionalidad social y la mayor inversión en las áreas sociales, principalmente en los programas de transferencias monetarias focalizadas. En el último quinquenio se ha estancado su disminución, a pesar de los cuantiosos recursos invertidos.

En ese contexto, el Gobierno de Mario Abdo Benítez (2018-2023), con mucho entusiasmo y decisión, promulgó la instalación de un 
Sistema de Protección Social (SPS), como mecanismo para institucionalizar las políticas sociales, buscando garantizar un piso mínimo de prestaciones estatales para que los ciudadanos y ciudadanas ejerzan su derecho constitucional "De la Calidad de Vida", en concordancia con la meta 1.3 de los Objetivos de Desarrollo Sostenible. El diseño y posterior puesta en marcha del SPS ha sido tomado con mucho aceptación y esperanza para gran parte de la academia y sociedad civil.

La configuración planteada del SPS consiste en 3 ejes principales (integración social, inclusión laboral y productiva y previsión social) que sirven de plataforma para coordinar los bienes y servicios prestados por el Estado, a favor de todos los ciudadanos, a lo largo de su ciclo de vida, características inherentes a un estado de bienestar. Es sin duda un gran desafío para el estado paraguayo en el orden político, económico e institucional, que requiere de la concreción de un gran pacto social a escala nacional.

Como colofón de las páginas precedentes, se puede concluir que el tránsito hacia un régimen de estado de bienestar para el Paraguay no va a ser fácil ni corto. Si bien, la exasperante inequidad y la vulnerabilidad social que afectan a gran parte de la población hacen que Paraguay sea un caldo de cultivo para gobiernos de corte autoritario, la fortaleza del status-quo alimentado por la cultura clientelar democratizada hace que se posterguen 0 apacigüen los connatos de revueltas $\mathrm{y} / \mathrm{o}$ el surgimiento de figuras populistas, sin mucho apego al juego democrático, que pretendan revertir el orden social establecido.

El dividir el estudio en tres fases ha permitido dimensionar que los tres elementos (voluntad política, ciclo económico favorable y estabilidad política), que se deben conjugar para un transitar hacia un Estado de Bienestar, no siempre estuvieron presentes al 
mismo tiempo, lo cual explica porqué, a pesar del incremento gradual en el gasto social, el avance del Paraguay es lento en los principales indicadores de desarrollo humano.

Pudo haber voluntad política, sumada a ciclos de auge económico, pero sin estabilidad/apoyo político no se hicieron sostenibles los esfuerzos a nivel burocrático para transformar al Estado (ciclo 2003-2013). Por el otro lado, se puede tener una envidiable estabilidad macroeconómica, una sólida legitimidad y gobernabilidad, pero sin la orientación programática adecuada, apenas lograr resultados muy desalentadores para el bienestar colectivo, como en el periodo 2013-2018.

Si bien los números del periodo de consolidación y tránsito al universalismo son elocuentes, la incapacidad de los actores políticos y la desarticulación de los movimientos sociales (campesinos, estudiantiles, obreros, en su mayoría sectores de la

99 población beneficiados por este giro en las políticas sociales), no pudieron construir un relato o discurso que aglutinase y acompañe las transformaciones en la gestión de las políticas públicas inclusivas, como conquistas de derechos ciudadanos, de abajo hacia arriba de cara al tránsito hacia un anhelado estado de bienestar.

La rigidez del sistema electoral paraguayo, que favorece en extremo al bipartidismo conservador, sumada a la atomización y constante conflicto interno entre las fuerzas progresistas, imposibilitan la transformación de arriba hacia abajo, a través de la cross-class coalition expresada por Esping-Andersen, citado más arriba. Los mismos actores que deben promulgar y velar por las transformaciones son los que se benefician del estatus-quo, por lo tanto, no encuentran motivación alguna para alterarlo.

Ante lo expuesto, este trabajo tiene como conclusión principal que, a pesar de la institucionalización de las políticas sociales en el 
Paraguay y la puesta en marcha de reformas y nuevos programas sociales para atender los derechos humanos de la ciudadanía, el estado paraguayo todavía dista bastante de cumplir con el mandato constitucional de garantizar la calidad de vida para todos/as.

La esperanza de los autores radica en que, para fortalecer y apoyar la consolidación del SPS, es necesario hablar en términos de estados y/o regímenes de bienestar en Paraguay, lo cual plantea analizar de una manera distinta y crítica la relación estado, mercado y sociedad. Cuanto mayor sea la apropiación al interior de los partidos políticos, de la academia paraguaya y esta, a su vez, tenga la capacidad de traducir los conceptos y mensajes claves a través de los medios de comunicación, mayor será la repercusión, análisis y debate en el ámbito de la sociedad civil, en la que finalmente radican las esperanzas de apropiarse y defender al SPS con el objetivo de transformar al país hacia un futuro con mayor prosperidad compartida, y sin dejar a nadie atrás, como está establecido en el Plan Nacional de Desarrollo y los Objetivos de Desarrollo Sostenible 2030.

\section{Referencias}

- Abente, D. y Masi, F. 2005. Estado Economía y Sociedad: Una Mirada Internacional a La Democracia Paraguaya. CADEP

- Abente D. 2012. Estatalidad y calidad de la democracia en Paraguay. AméRica Latina Hoy, 60, 43-66. doi:10.14201/alh.8973

- Abente, D. 2007. The quality of democracy in small south American countries: The case of Paraguay. Working Paper of the Helen Kellogg Institute for International Studies.

- Banco Mundial. 2018. Paraguay. Invertir en capital humano: una revisión del gasto público y la gestión en los sectores sociales. ( ) 
World Bank. Disponible en http://documentos.bancomundial.org/curated/es/2065015427445 71707/pdf/132203-SPANISH-WP-v1-PER-Chapter-1MacroFiscal-19-11-18.pdf

- Bareiro, L. 2003. Tres Nicanores distintos y un solo presidente del Paraguay ¿Cuál será el verdadero?. En Nicanor Presidente 2003-2008 - ¿Un "Tendota" para el Paraguay?. Revista NOVAPOLIS Edición Número 4, agosto 2003

- Borda, D. 2007. Paraguay: resultados de las reformas 2003-2005 y sus perspectivas. Comisión Económica para América Latina y el Caribe. Santiago.

- Dirección General de Encuestas Estadísticas y Censos. 2018. Principales indicadores de pobreza de la población por año de la encuesta, según área de residencia. Período 1997/98.

Recopilado de:

https://www.dgeec.gov.py/assets/documento/61305Pobreza_py_ EPH\%201997-98_2018.xls

- Duarte-Recalde, L. 2014. Concentración del poder político y debilitamiento estatal durante el gobierno cartista. En Revista Novapolis. No 7, Abr-Oct 2014, pp. 37-52. Asunción: Arandurã Editorial

- Galeano, L. 2005. "El combate a la pobreza en Paraguay", In Rivarola, D. (ed.), Política Social en la transición, Asunción, CPES. Ediciones y Arte Libros.

- Nickson, A. y Lambert, P. 2002. 'State Reform and the Privatized State' in Paraguay', Public administration and development.

- Esping-Andersen, G. 1990. The Three Worlds of Welfare Capitalism. Cambridge: Polity Press.

- Gough, I. y Wood, G. S/F. Insecurity and Welfare Regimes in Asia, Africa and Latin America: Social Policy in Development Contexts, Cambridge: Cambridge University Press

- Hopkin, J. 2006. Clientelism and party politics. En Crotty \& Katz, Handbook of Party Politics (págs. 406-412). London: SAGE

- Lachi, M. 2015. Pertenencia partidaria en Paraguay. Un estudio de caso sobre el electorado del departamento de Ñeembucú, y su comportamiento en las elecciones de 2013. Novapolis, 117137. 
- Lachi, M. y Rojas Scheffer, R. 2018. y prácticas políticas del electorado paraguayo - 1a edición Asunción: Centro de Estudios y Educación Popular Germinal y Arandurã Editorial.

- Morínigo, J.N. 2005. La práctica del Orekueté como matriz de la discriminación política. En Bareiro, L., (ed) Discriminaciones. Debate teórico paraguayo. Legislación antidiscriminatoria. Asunción:CDE

- Morley, S. y Vos, R. 1997. Poverty and Dualistic Growth in Paraguay. The Hague: Institute of Social Studies.

- Organización para la Cooperación y el Desarrollo Económicos. 2018. Estudios de la OCDE sobre Gobernanza Pública: Paraguay: Hacia un desarrollo nacional mediante una gobernanza pública integrada, Éditions OCDE, Paris. Accesible en https://doi.org/10.1787/9789264304017-es

- Ortiz, L.; González, I. y Gómez, C. 2015. Sistema político y desigualdad social en Paraguay. en torno al proceso gubernamental de 2008-2012 en Francisco J. Cantamutto [et al.] De la democracia liberal a la soberanía popular. Gobiernos latinoamericanos: los desafíos del Estado, la acumulación y la seguridad Ciudad Autónoma de Buenos Aires : CLACSO, 2015.

- Rivarola, M. 2018. Políticas fiscales y desigualdad en Paraguay en Rivarola, M. (ed), Programa Paraguayo Para el Desarrollo de la y Tecnologia, CONACYT, Campaña por la Expresión Ciudadana, CADEP. Fiscalidad Para La Equidad Social. (Primera edición) Asunción, Paraguay: Decidamos, Campaña por la Expresión Ciudadana.

- Rojas, J. 2017. Coordination and implementation of anti-poverty strategies: the case of Paraguay. Social Policy for Development (SPD). https://www.academia.edu/36209375/COORDINATION_AND_IM PLEMENTATION_OF_ANTI-

\section{_POVERTY_STRATEGIES_THE_CASE_OF_PARAGUAY}

- Rojas, J. 2018a. El sistema clientelar paraguayo y su influencia en el Régimen de Inseguridad Social. Terere Cómplice Blog de Análisis Político. Disponible

en 
https://tererecomplice.com/2018/09/19/el-sistema-clientelarparaguayo-y-su-influencia-en-el-regimen-de-inseguridad-social/

- Rojas, J. 2018b. Desafíos político-institucionales del sistema de protección social - Vamos!. En Revista Paraguay desde las Ciencias Sociales, revista del Grupo de Estudios Sociales sobre Paraguay, no 9, 2018, pp. 66-86 Instituto de Estudios de América Latina y el Caribe, Universidad de Buenos Aires. Argentina

- Rojas Viñales, A. 2018. Determinantes estructurales de la política social del Estado Paraguayo: Alimentaria a Adultos Mayores". Universidad Autónoma de Zacatecas.

- Sampó, C. 2007. Las Falencias del Estado paraguayo desde la apertura democrática. Revista Enfoque Social. Revista de Historia, Política y Sociedad. Universidad de Tamaulipas, México.

- Serafini, V. y Zavattiero, C. 2018. La Protección Social En El Paraguay; Avances y Desafíos Para La Garantía De Derecho, Revista MERCOSUR de políticas sociales 2: 173.

- Uribe Gómez, M. 2018. Ciclos políticos y política social en América Latina en el Siglo XXI. Forum Revista Departamento de Ciencia Política. (13): 101-118.

- Wood, G. 2004. "Informal security regimes: the strength of relationships". In Gough, Ian. and Wood, George. (eds) Insecurity and Welfare Regimes in Asia, Africa and Latin America: Social Policy in Development Contexts, Cambridge: Cambridge University Press.

- Duarte-Recalde, L.R. 2018. La institucionalidad de la política de asistencia social en Paraguay en La Asistencia Social en Argentina y América Latina. Avances, problemas y desafíos. Andrenacci, Luis ; Campana, Mario; Servio, Matias. (eds) - 1a ed. - Rosario: Pegues. 